\title{
Change of perceived ICT skills of medical studentsover four years: a follow up study
}

\author{
Dr. MahindaKommalageMBBS, PhD \\ Senior Lecturer, Department of Physiology, Faculty of Medicine, University of Ruhuna, Sri Lanka \\ E-Mail address: mahinda1@gmail.com
}

Sri Lanka Journal of Bio-Medical informatics 2011:2(3):102-106

DOI: http://dx.doi.org/10.4038/sljbmi.v2i3.4286

\begin{abstract}
Information and Communication Technology (ICT) skills of doctors are a great advantage when implementing ICT based components in health services. ICT skills acquired by medical undergraduates will be beneficial in their career. Medical undergraduates are involved in many ICT related assignments during their trainingin the Faculty of Medicine, University of Ruhuna. The aim of this study is to investigate the improvement of perceived ICT skills during a four-year study period in a group of medical students.

Perceived ICT knowledge of a single group of medical undergraduates in the University of Ruhuna was investigated duringtheir first year and fourth year using the same questionnaire. Several aspects of ICT knowledge such as ability to prepare documents using Microsoft Word (MS Word), composing and sending emails, browsing the internet and finding required information were assessed in the questionnaire. A score was calculated for each skillobtainedfor MS Word, e-mail and Internet skills.

Results reveal thatonlyinternet, e-mail and the total ICT scores showed significant improvement, while MS Word skills did not change significantly. Females showed significant development in internetskills and the total ICT scores whereas males did not show such a significant change.

This shows that perceived ICT skills in relation to internet and email skills have improved during the studentsô stay at the Medical Faculty. This was not seen in MS Word skills. Female students who had comparatively poor skills during their first year showed greater improvement than their male counterparts.
\end{abstract}

Keywords-perceived ICT skills; ICT in Medical Faculty; gender difference in ICT

\section{Introduction}

ICT can be a powerful tool for those working in the health sector if resources and knowledge are given adequately. ICT can be used to improve many aspects of the health care service such as health care delivery, medical information systems and communication.

ICT skills are essential for the effective use in the health care delivery system. DoctorsôICT skill will be a great advantage in implementing programmes in health services. Therefore, ICT skills acquired by medical undergraduates will be beneficial to them in theircareer as doctors.

Previous ICT based activities introduced in the undergraduate curriculum in the Faculty of Medicine, University of Ruhuna have had mixed results ${ }^{(1,2)}$. One reason for failure was poor ICT skills of the undergraduates ${ }^{(3)}$.

A clear difference can be seen in ICT skills in students in theMedical Facultyin the

University of Ruhunawhen compared to students in developed countries ${ }^{(1,4,5)}$. One of the main factors that contribute to ICT skills is their pre-existing knowledge before entering the 
Medical Faculty. Only some schools offer ICT training for students resulting in a discrepancy in skills among students that enter the Medical Faculty ${ }^{(3)}$.

Students also undergo ICT related assignments as a part of their study in theMedical Faculty. These assignments could becompulsory individual componentsor group activities. Students are provided with many ICT resources such as computer labs, internet connection, wireless network, ICT based learning material and online lecture notes distribution. These resources and assignments aim to and should have helped to improve the use of ICT skills in undergraduates. The aim of this study was to investigate improvement of perceived ICT skills during the study period in a group of medical students..

\section{Methods}

Perceived ICT skills in a single group of medical undergraduates in the University of Ruhuna were assessed in the first year and fourth year using the same questionnaire. The aspects of ICT skill assessed in the questionnaire were:perceived ability for preration of documents using MS Word, composing and sending e-mails, and browsing the internet and searchingfor information.

Students were asked to grade their abilities on use of MS Word, e-mail, and the interneton a

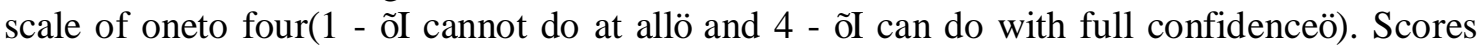
were separately calculated for different tools MS Word, e-mail, and internet. Points were allocated according to the following: Students who responded with ñ can do with full confidenceò, ñ can do without helpò, ñ can do with some helpò and ñ canâ do at allò were allocated 4, 3, 2 and 1 points respectively. The total ICT score was calculated by adding the scores for MS Word, e-mail, andinternetskills.

The first assessment was conducted in 2007 during the studentsôfirst term. All first year students were requested to volunteer. A questionnaire was introduced to students after a noncompulsory formal lecture. The second assessment was conducted in 2010 when the same students were in theirfourth year. Since it was difficult to get all the students who initially participated, students were randomly selected from the batch. Notices were displaced requesting them to participate in the study. On the day of the study, students were requested to assemble at a designated location and the questionnaire was distributed.

\section{Results}

124 students participated in the first assessment. 27(21.7\%) students from the group were randomly selected for the second assessment. Only 25 students participated in the second assessment and one student provided incomplete information. Finally a total of 24 students from second assessment and 27 students from first assessment were selected for comparison.Number of students and their scores for MS word, e-mail, and internet skills in the first and fourth years are shown in table 1.

The total IT scoreswere 7.77 (SD 2.47) and 9.79 (SD 2.68) in first year and fourth year respectively, which was a significant improvement ( $\mathrm{p}<0.01$ by t-test). Only internetand e-mail skills showed significant improvement $(\mathrm{p}<0.01$ and $\mathrm{p}<0.05$ Pearson chi-square for internetand e-mail respectively).MS Word skills did not change significantly. 
Table 1.Number of students and their grades for MS word, e-mail, and internet skills in the first and fourth years.

\begin{tabular}{|l|c|c|c|}
\hline & Grades & 1st year & 4th year \\
\hline MS Word & 1 & 1 & 2 \\
\cline { 2 - 4 } & 2 & 10 & 4 \\
\cline { 2 - 4 } & 3 & 12 & 7 \\
\cline { 2 - 4 } & 4 & 4 & 11 \\
\hline E-mail & 1 & 0 & 1 \\
\cline { 2 - 4 } & 2 & 8 & 4 \\
\cline { 2 - 4 } & 3 & 13 & 5 \\
\cline { 2 - 4 } & 4 & 4 & 14 \\
\hline Internet & 1 & 0 & 1 \\
\cline { 2 - 4 } & 2 & 12 & 5 \\
\cline { 2 - 4 } & 3 & 10 & 3 \\
\cline { 2 - 4 } & 4 & 3 & 15 \\
\hline
\end{tabular}

Changes were also compared separately based on gender. Overall IT scores of female students improved significantly from 7.68 (SD 2.05) to $9.90(2.46)(\mathrm{p}<0.05 \mathrm{t}$-test). Internet and e-mail skills of female students showed significant improvement $(\mathrm{p}<0.05$ Pearson chisquare for both e-mail and internet). IT skills of male students did not show significant change during this period.

\section{Discussion}

After four years of study in the Medical Faculty, students showed some improvement in their perceived ICT skills. A prominent improvement in internet skills which was comparatively poor in the first year was observed. Their ability to use e-mail also showed some improvement. Overall e-mail and internet skills were lower than MS Word skills in the first year undergraduates in theMedical Faculty ${ }^{(1)}$. This study showed that some of the relatively poor skills have improved during a four year study period in the Medical Faculty.

Several ICT related assignments were conducted for undergraduates of theMedical Faculty.Most of these assignments were guided self studies using internet resources, short analytical essay writing, student seminars and tutorials which required self study using internetresources $^{(1,2)}$. In these assignments, students were supposed to use internet, e-mail, Word processing, presentation software and some other ICT related resources. Results of some of the assignmentshave been reported previously ${ }^{(2)}$.

As internet and e-mail are very popular communication tools, they may have been used by students for non-academic purposes whereas students probably had only limited opportunities to use MS Word, even for non-academic purposes during this four year study in the Medical Faculty. This maybe one reason why word processing skills did not change as was the case with e-mail and internet skills. 
Overall ICT skills in Sri Lankahad improved during this four year period ${ }^{(6)}$. Availability of PCs and related devices such as Personal Digital Assistants (PDA) and mobile phones showed an overall increase during this period. These improvements may also have influenced the development of ICT skills of the medical undergraduates.

Improvement of ICT skills in this study showed clear gender discrepancy by femalestudents showing a better improvement than malestudents. Total ICT score and internet use improved significantly only in female students. This difference maybe partly due to the poor ICT learning that female students had in their schools ${ }^{(1)}$. However, at the end of four years of study in the Medical Faculty the female students have improved their ICT skills to be on par with their male counterparts.

Despite these results ICT skills were still poor in these students compared to students in developed countries. Lack ofICT competence ofthe health care work force ${ }^{(7)}$ was highlighted as a drawback in introducing ICT components in health care service in developing countries. A reason for the poor ICT use among doctors and certain health care professionals was lackingin the ICT training in these countries and one recommendation was to improve ICT skills ofundergraduates ${ }^{(8,9)}$. Therefore, the need to introduce a more systematic training programme in ICT and opportunities to use ICT for medical undergraduates is essential. This result can be applicable for many other Medical Faculties in Sri Lanka where students come from similar socio-economic backgrounds.

The limitations that can be identified in this study were: using only a randomly selected sample of fourth year students and assessing only the perceived ICT capabilities. Some students may be more self confident and have a higher perception about their capabilities which may have affected the results of the study.

In conclusion perceived ICT skills have improved in students during their study period in the Faculty of Medicine, University of Ruhuna. Internet and e-mail skills which were poor when they were studying in the first year showed improvement. Female students who had comparatively poor skills in the first year showed better improvement than male students.

\section{References}

1. Kommalage M, Gunawardena S. IT-based activity in physiology education: an experience from a developing country. AdvPhysiolEduc2008, 32:81-85.PMID:18334573[PubMed indexed for MEDLINE]

2. Kommalage M, Gunawardena S.Introduction of analytical essay writing activity in the medical curriculum. In: $A M E E$ 2008: Prague, Czech Republic: Association for Medical Education in Europe; 2008: Abstract, 9w/p5.

3. Kommalage M, Gunawardena S. Feasibility of introducing information technology-based activities into medical curricula in developing countries. Med Educ2008, 42:113.PMID:18181850[PubMed - indexed for MEDLINE] 
4. Dorup J. Experience and attitudes towards information technology among first-year medical students in Denmark: longitudinal questionnaire survey. $J$ Med Internet Res 2004, 6:e10.http://dx.doi.org/10.2196/jmir.6.1.e10

5. Peterson MW, Rowat J, Kreiter C, Mandel J. Medical students' use of information resources: is the digital age dawning? Acad Med 2004, 79:89-

95.PMID:14691004[PubMed - indexed for MEDLINE]

6. Sri Lanka Computer Literacy Survey - 2009.

http://www.statistics.gov.lk/CLS/BuletinComputerLiteracy_2009.pdf Accessed on 25-062010.

7. Oak M: A review on barriers to implementing health informatics in developing countries.Journal of Health Informatics in Developing Countries 2007, 1:19-22.

8. Bello IS, Arogundade FA, Sanusi AA, Ezeoma IT, Abioye-Kuteyi EA, Akinsola A: Knowledge and utilization of InformationTechnology among health care professionals and students in Ile-Ife, Nigeria: a case study of a university teaching hospital. $J$ Med Internet Res 2004, 6:e45.http://dx.doi.org/10.2196/jmir.6.4.e45

9. Asangansi IE, Adejoro OO, Farri O, Makinde O: Computer use among doctors in Africa: survey of trainees in a Nigerian teaching hospital. Journal of Health Informatics in Developing Countries 2008, 2:10-14. 